\title{
Factors associated with the utilization of antenatal care and prevention of mother- to-child HIV transmission services in Ethiopia: applying a count regression model
}

\author{
Elias Asfaw Zegeye ${ }^{1,2^{*}}$ (D) Josue Mbonigaba ${ }^{1}$ and Zacharie Tsala Dimbuene ${ }^{3}$
}

\begin{abstract}
Background: Prevention of Mother-to-Child HIV Transmission (PMTCT) coverage has been low in Ethiopia and the service has been implemented in a fragmented manner. Solutions to this problem have mainly been sought on the supply-side in the form of improved management and allocation of limited resources. However, this approach largely ignores the demand-side factors associated with low PMTCT coverage in the country. The study assesses the factors associated with the utilization of PMTCT services taking into consideration counts of visits to antenatal care (ANC) services in urban high-HIV prevalence and rural low-HIV prevalence settings in Ethiopia.

Methods: A multivariate regression model was employed to identify significant factors associated with PMTCT service utilization. Poisson and negative binomial regression models were applied, considering the number of ANC visits as a dependent variable. The explanatory variables were age; educational status; type of occupation; decisionmaking power in the household; living in proximity to educated people; a neighborhood with good welfare services; location (urban high-HIV prevalence and rural low-HIV prevalence); transportation accessibility; walking distance (in minutes); and household income status. The alpha dispersion test (a) was performed to measure the goodness-of-fit of the model. Significant results were reported at $p$-values of $<0.05$ and $<0.001$.

Results: Household income, socio-economic setting (urban high-HIV prevalence and rural low-HIV prevalence) and walking distance (in minutes) had a statistically significant relationship with the number of ANC visits by pregnant women $(p<0.05)$. A pregnant woman from an urban high-HIV prevalence setting would be expected to make $34 \%$ more ANC visits (counts) than her rural low-HIV prevalence counterparts $(p<0.05)$. Holding other variables constant, a unit increase in household income would increase the expected ANC visits by $0.004 \%$. An increase in walking distance by a unit (a minute) would decrease the number of ANC visits by $0.001(p<0.001)$.

Conclusion: Long walking distance, low household income and living in a rural setting are the significant factors associated with low PMTCT service utilization. The primary strategies for a holistic policy to improve ANC/PMTCT utilization should thus include improving the geographical accessibility of ANC/PMTCT services, expanding household welfare and paying more attention to remote rural areas.
\end{abstract}

Keywords: PMTCT service, Ethiopia, Urban-rural settings, Count regression, Utilization analysis

\footnotetext{
* Correspondence: eliasasfawe@gmail.com

${ }^{1}$ School of Accounting, Economics and Finance, Economics Department,

University of KwaZulu-Natal, Durban, South Africa

${ }^{2}$ Clinton Health Access Initiative, Health Care Financing Program, Addis

Ababa, Ethiopia

Full list of author information is available at the end of the article
}

(c) The Author(s). 2018 Open Access This article is distributed under the terms of the Creative Commons Attribution 4.0 International License (http://creativecommons.org/licenses/by/4.0/), which permits unrestricted use, distribution, and

reproduction in any medium, provided you give appropriate credit to the original author(s) and the source, provide a link to the Creative Commons license, and indicate if changes were made. The Creative Commons Public Domain Dedication waiver (http://creativecommons.org/publicdomain/zero/1.0/) applies to the data made available in this article, unless otherwise stated. 


\section{Background}

Globally, 36.7 (34.0-39.8) million people were living with HIV/AIDS, $2.1(1.8-2.4)$ million were newly infected with HIV, and about 1.1 (940,000-1.3) million people had died of HIV/AIDS in 2015 [1]. Over time, an increasing number of people living with HIV, and decreases in new HIV infections and AIDS-related deaths have been reported [1-3]. For instance, new HIV infections in 2015 were 5\% lower than in 2010 [1], while they were $20 \%$ lower in 2011 than in 2001 [2]. UNAIDS further reported a decrease of $33 \%$ in HIV infections between 2001 and 2012 [3].

The overall decline in new infections and deaths can be partly attributed to the effectiveness of prevention, behavioral changes and treatment interventions [1, 4, 5]. However, low uptake of interventions targeting pregnant women and infants in low- and middle-income countries (LMICs) persists. According to UNAIDS, approximately $38 \%$ of HIV-exposed pregnant women and $65 \%$ of HIV-infected infants, mainly in LMICs, have no access to antiretroviral therapy (ART) services [3]. A minimal improvement from 64 to $68 \%$ Prevention of Mother-to-Child HIV/AIDS Transmission (PMTCT) coverage was reported during the period 2012-2013 [6] and this increased to $77 \%$ in 2015 (UNAIDS, 2016). The situation was worse in sub-Saharan African (SSA) countries where PMTCT services were underutilized and weak $[2,7]$. In the 21 priority countries, AIDS-related mortality ( $<15$ years) decreased by $53 \%$ between 2009 and 2015 [1].

Low levels of service uptake among pregnant women attending antenatal care (ANC) are a critical bottleneck in PMTCT interventions as these integrated services are a primary entry point for comprehensive PMTCT service. For instance in 2015, only $34 \%$ of pregnant women accessed lifelong antiretroviral treatment [6]. Some countries also reported a decrease in PMTCT service utilization between 2012 and 2013 [6]. PMTCT service uptake was uneven due to differences between health systems and fragile due to social factors [6-8]. Limited utilization has important implications given the fact that PMTCT is at the center of health improvement among the most vulnerable segment of the population, notably women and children.

A systematic review revealed that utilization of PMTCT services was hampered by many challenges including patient-related factors, socio-cultural barriers, negative family influence, poor adherence, inadequate diagnostic laboratory facilities and a lack of effective community participation (Adetokunboh and Oluwasanu, 2015). Thus, despite the cross-cutting role of PMTCT in reducing new infant infections and prolonging women's life expectancy, utilization of these services has been inadequate. These points to the need for improved PMTCT program management, particularly in low-income countries like Ethiopia that carry a substantial portion of the pandemic burden.

\section{PMTCT service utilization}

The few studies that have analyzed PMTCT service utilization in Africa, including in South Africa, Uganda and Burkina Faso [9-14] reported different barriers to effective PMTCT service uptake. These include health facility inaccessibility, long distances, poor infrastructure, poverty, inadequate knowledge of PMTCT, service quality, limited family and community support, inaccessible rural communities and partners' influence. Adetokunboh and Oluwasanu highlighted the need for more information on health service utilization to achieve the elimination of mother-to-child HIV transmission. Overall, demand-side PMTCT service utilization has received inadequate research attention in SSA countries [8].

Utilization of PMTCT services has also been at the center of policy debates. Extending the vision of the Joint United Nations Program on HIV/AIDS (UNAIDS) to achieve zero infant infections by 2015 [3, 15], the United Nations (UN) Sustainable Development Goals (SDG) adopted in September 2015 set the goal of a major reduction in maternal and child deaths as well as universal access to reproductive health services by 2030 [16]. Given growing income inequalities, PMTCT service utilization is expected to vary across urban-rural settings due to enabling factors on the one hand and barriers on the other, related in particular to service accessibility and improving coverage. However, only a few studies are reported in South Africa and Uganda, which assessed program implementation across different socio-economic, structural and urban-rural settings $[11,17]$.

As in most SSA countries, there is limited evidence on the utilization of PMTCT services in Ethiopia. This problem is significant as the disease has become more heterogeneous across urban-rural settings in this country [18], and service uptake is likely to be low in remote rural settings as compared to urban areas. Different confounding factors such as knowledge, educational attainment, and partner influence and facility accessibility have also negatively affected rural women $[19,20]$.

PMTCT services in Ethiopia are characterized by low coverage [21]. This led UNAIDS to identify it as one of the 21 countries that require high-priority action [3]. In 2012, UNAIDS noted that Ethiopia had achieved less than 50\% ART coverage for pregnant women living with HIV [3]. The 2011/12 Ministry of Health Annual Performance Report noted that a total of 9775 HIV-positive mothers had received ART treatment in the 2004 financial year (Ethiopian Fiscal Year/EFY), far below the target $(38,405)$ [2]. Coverage increased from $9.3 \%$ of the target in $2010 / 11$ to $25.5 \%$ in $2011 / 12$, indicating unsatisfactory progress [22]. 
However, none of the above studies assessed PMTCT program utilization within the context of urban-rural HIV heterogeneity (high, low) settings. Given that this epidemic is heterogenous across urban-rural settings, it is worth generating evidence (applying regression models) to enable policy makers to take different factors into account, such as those that are patient related and those associated with demographics and socio-economic circumstances (urban high-HIV prevalence vis-à-vis rural low-HIV prevalence settings) that affect service utilization. Such an analysis should inform overall PMTCT program implementation and lead to improved service coverage across the country. To this end, this study assessed the factors associated with PMTCT service utilization using data on pregnant women from ANC/PMTCT integrated services in Ethiopian health care facilities.

\section{Methods}

\section{Study settings}

The selection of participating health facilities in this study was based on the 2012 ANC sentinel surveillance of PMTCT by the Ethiopian Public Health Institute (EPHI) [23, 24]. The EPHI identified 117 ANC facility sites in different geographical regions in the country and found that HIV prevalence in these facilities ranged from 0.01 to $17 \%$. Six facilities with the highest HIV prevalence (between 8.1 and 17\%) and six with the lowest HIV prevalence $(<0.1 \%)$ were purposively enrolled. The choice of highest and lowest HIV prevalence health facilities (ANC-PMTCT sites) was informed by the need to obtain a clear and comprehensive picture of the factors associated with the utilization of ANC-PMTCT services across high HIV prevalence versus low prevalence areas. Given that urban settings have higher HIV prevalence, the six facilities with the highest prevalence were from urban areas, and the six with the lowest prevalence were in rural settings. This offered an opportunity to assess the effect of existing interventions in urban high-HIV prevalence/rural low-HIV prevalence areas from the perspective of PMTCT service utilization. The selected health facilities are in Amhara, South Nation and Nationality People (SNNP), Oromia, Harrar, Dire Dawa and Addis Ababa regions, where $85 \%$ of the country's population resides [25]. Table 1 describes the facilities included in the study.

\section{Sample size estimation}

The study population for the survey comprised of pregnant women attending ANC/PMTCT services at the surveyed health facilities. As the PMTCT service is well-integrated with ANC in these facilities, utilization evidence was collected from pregnant women attending the ANC service. As noted previously, ANC is the primary entry point for the PMTCT service package that comprises pre-HIV test counseling, testing, post-test counseling and enrollment in lifelong antiretroviral treatment. Every pregnant woman attending ANC would be expected to utilize the PMTCT service package. With this framework, the sample for ANC/PMTCT service utilization was computed using a single proportion formula, 95\% confidence interval, 5\% margin of error, the proportion of $42 \%$ of HIV-positive tested women and a non-response rate of $10 \%$, and assuming a homogenous population of pregnant women attending the health facilities [26, 27]. Applying the formula, the minimum required sample size was calculated as 449 .

A relatively large sample of 484 pregnant women was used to analyze the factors associated with demand-side utilization of PMTCT services. These women were accessed through simple random sampling of past ANC/ PMTCT records of visits (from the registration book) across the 12 health facilities. Using the visit records, the total sample size was proportionally apportioned across the surveyed health facilities. Based on the inclusion

Table 1 List of study sites, including HIV prevalence and location of health facility

\begin{tabular}{|c|c|c|c|c|}
\hline Surveyed health facilities & Region & HIV prevalence & Region & Settings \\
\hline Bahir Dar Hospital & Amhara & 17.30 & Northern Ethiopia & Urban high-HIV prevalence \\
\hline Hiwot Fana Hospital & Harar & 8.82 & Eastern Ethiopia & Urban high-HIV prevalence \\
\hline Dile Chora Hospital & Dire Dawa & 8.12 & Eastern Ethiopia & Urban high-HIV prevalence \\
\hline AFRTH Hospital & Addis Ababa & 8.70 & Addis Ababa & Urban high-HIV prevalence \\
\hline Soddo Health Center & SNNPR & 8.81 & Southern Ethiopia & Urban high-HIV prevalence \\
\hline Teklehaimanot Health Center & Addis Ababa & 8.83 & Addis Ababa & Urban high-HIV prevalence \\
\hline Limuseka Health Center & Oromia & 0.02 & Western Ethiopia & Rural low-HIV prevalence \\
\hline Daddim Health Center & Oromia & 0.04 & Western Ethiopia & Rural low-HIV prevalence \\
\hline Toke Health Center & Oromia & 0.01 & Western Ethiopia & Rural low-HIV prevalence \\
\hline Chewaka Health Center & Oromia & 0.05 & Western Ethiopia & Rural low-HIV prevalence \\
\hline Kokosa Health Center & Oromia & 0.02 & Eastern Ethiopia & Rural low-HIV prevalence \\
\hline Hasange Health Center & Harar & 0.03 & Eastern Ethiopia & Rural low-HIV prevalence \\
\hline
\end{tabular}

Source: ANC sentinel HIV/AIDS PMTCT surveillance report (EPHI, 2014) 
criteria, every pregnant woman reporting for ANC/ PMTCT service visits during the study period had an equal chance of being selected.

Women attending other reproductive health services, including family planning were not included. If the pregnant woman had come with her partner (husband) to the health facility, conditional on her consent, the husband would be included in the interview but the response was finally recorded for the pregnant woman. Once the respondents agreed, data collection was conducted in an appropriately designated and confidential space within the health facility premises, assisted by a trained data collector. Data collectors were trained over two days on the data instruments and relevant data variables. If a pregnant woman withdrew during the course of the interview, she would be replaced by the next, consecutive randomly sampled pregnant woman. This process was repeated until the required proportionally allocated sample limit was reached per health facility.

The data was collected using a structured questionnaire, which was adapted from a similar ANC survey conducted in Ethiopia [28], and piloted in two health facilities in Addis Ababa, namely, Gandhi Memorial Hospital and Beletsheachew Health Center. The questionnaire consisted of sections on socio-demographic characteristics; information about the visit; HIV/AIDS counseling and testing; socio-economic status; out-of-pocket (OOP) spending; household income and spending, and related socio-cultural factors. It was translated back into the national language, Amharic.

\section{Regression model}

The count model was applied to analyze the frequencies/counts of the pregnant women's ANC visits (including first through to eighth visits) at the health facilities. The minimum and maximum recorded visits (during the survey) ranged from one to eight, respectively. The dependent variable was the reported number of visits for ANC initiation or follow-up. The basic assumption was that a pregnant woman with a large number of visits (counts) during her pregnancy would be more likely to use the PMTCT service. Because the number of ANC visits was considered as the dependent variable $(\mathrm{Y})$ in the model, count regression (Poisson and negative binomial) models were the most appropriate to assess the statistically significant factors associated with PMTCT service utilization. The distribution of the ANC visits and mean and variance of the dependent variable is presented in Table 2 and Fig. 1.

As shown in Fig. 1, the data was skewed to the right, which calls for application of the count model, either the Poisson or negative binomial model. The relevant statistical analysis software was applied to estimate the mean and variance demands for the appropriateness of the
Table 2 Mean and variance of the dependent variable (number of ANC visits by the pregnant women)

\begin{tabular}{|c|c|c|c|c|}
\hline \multicolumn{5}{|c|}{ Total number of visits (for the count regression model) } \\
\hline & Percentiles & Smallest & & \\
\hline $1 \%$ & 1 & 1 & & \\
\hline 5 & 1 & 1 & & \\
\hline $10 \%$ & 1 & 1 & obs & 482 \\
\hline $25 \%$ & 1 & 1 & Sum of Wgt. & 482 \\
\hline \multirow[t]{2}{*}{$50 \%$} & 2 & & Mean & 2.134855 \\
\hline & & Largest & Std. Dev. & 1.508282 \\
\hline $75 \%$ & 3 & 8 & & \\
\hline $90 \%$ & 4 & 8 & Variance & 2.274916 \\
\hline $95 \%$ & 5 & 8 & Skewness & 1.5466144 \\
\hline $99 \%$ & 7 & 8 & Kurtosis & 5.233386 \\
\hline
\end{tabular}

count model analysis. The mean count variable was 2.13, which was similar to the variance result (2.27). If the mean and variance of the dependent variables are equal, the Poisson regression model would best fit the dependent variable of interest (i.e., the number of ANC visits by a pregnant woman) [29].

The Poisson model determined the probability that the regressed variable $(\mathrm{Y})$ occurs at a specific time interval. The probability is modeled as:

$$
\begin{aligned}
& \rho(Y=y)=\frac{e^{-\mu} \mu^{y}}{y !} \\
& \mu=\exp \left(x_{i} \beta\right)
\end{aligned}
$$

Where,

$\mathrm{Y}_{\mathrm{i}}=$ number of pregnant women attending ANC visits (1st, 2nd, 3rd... 8th);

$\mu=$ the intensity or rate parameter;

$\mathrm{Xi}=$ are the explanatory variables.

The variables represented by $\mathrm{Xi}$ in Eq. 1.2, were age; educational status; type of occupation; decision-making power in the household; living in proximity to educated people; a neighborhood with good welfare services; location (urban high-HIV prevalence, rural low-HIV prevalence); transportation accessibility; walking distance (hours/minutes); and household income status. In addition, the dummy variable on the socio-economic location and HIV prevalence setting variable were used jointly (urban high-HIV prevalence vis-à-vis rural low-HIV prevalence) as a relevant explanatory variable. Some of the independent variables were continuous, while others were categorical (dummy) variables.

The second count regression model was the negative binomial model. It is similar to the count regression model but with a different functional form and the equidispersion property (mean and variance equality) in the 


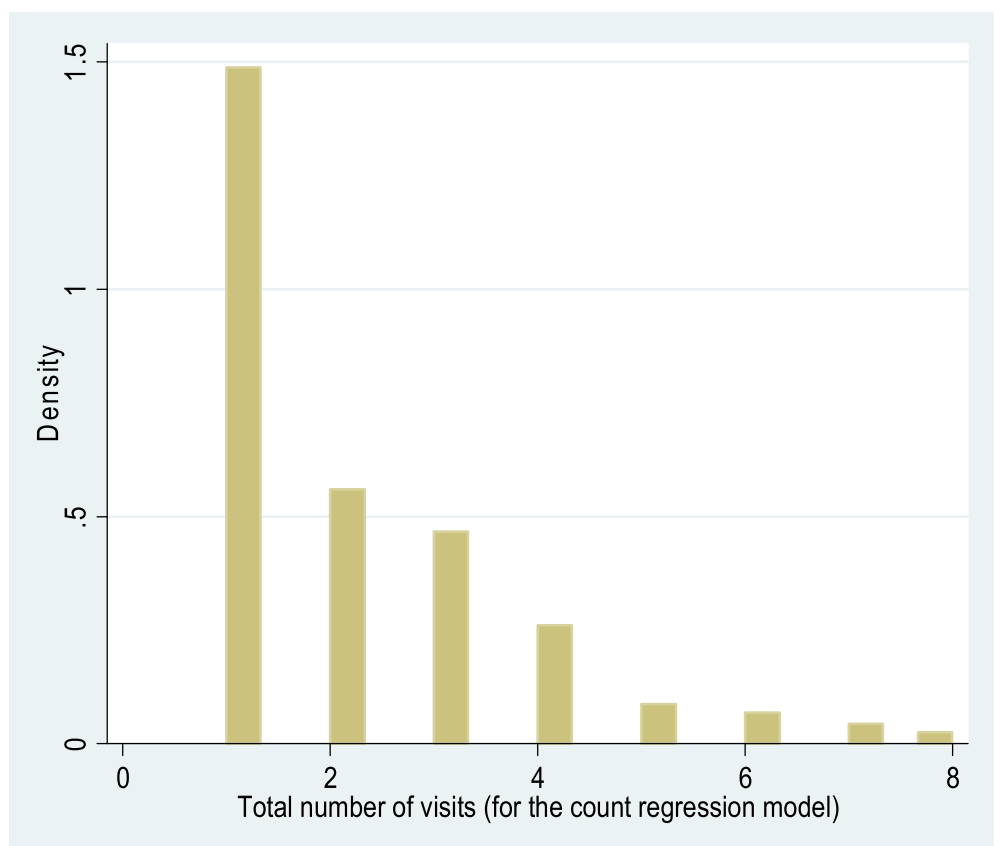

Fig. 1 Histogram showing the density of the number of antenatal care visits (for the count regression model)

Poisson model is relaxed. The negative binomial model was primarily applied to strengthen the findings from the Poisson regression model, and estimate the alpha dispersion $(\alpha)$ tests. The negative binomial model, which allows the variance and the mean not to be equal, was written as follows:

$$
\operatorname{var}(y \mid x)=\mu+\alpha \mu^{2}
$$

This model also tests $(\alpha)$ the "measure of over dispersion" and was used to strengthen the choice of the Poisson model. According to the null hypothesis $\left(\mathrm{H}_{\mathrm{o}}: \alpha=0\right.$ or $\mathrm{H}_{\mathrm{a}}: \neq 0$ ), tests whether $\alpha$ is significantly different from zero can yield three different outcomes: 1) if $\alpha=0$, no dispersion (this shows the appropriateness of the Poisson model), 2) if $\alpha>0$, over dispersion and 3) if $\alpha<0$, under dispersion.

\section{Results}

Of the 484 pregnant women attending the health facilities who were interviewed, $49 \%$ were from urban high-HIV prevalence settings, while $51 \%$ lived in rural low-HIV prevalence areas. The mean age of the respondents was 27 and 25 years in the urban and rural settings, respectively. The majority of the respondents in urban high-HIV prevalence settings (more than 57\%) had completed secondary school (grades 9 \& 10) or above, while most of the rural low-HIV prevalence interviewees (more than 86\%) were illiterate. A statistically significant difference in terms of educational attainment was thus found between women from urban high-HIV prevalence and rural low-HIV prevalence areas attending ANC $(p<0.001)$. In both settings, most of the pregnant women did not have a formal occupation, and worked as housewives. The respondents depended on their partner/ husband and his sources of income. A relatively higher proportion of pregnant women in urban high-HIV prevalence settings had permanent paid jobs (25\%) and they were involved in trade or business-related activities (17\%). However, in the rural low-HIV prevalence settings, most women worked in farming and agriculture. Permanent paid work in the urban high-HIV prevalence areas and farming and agriculture in the rural low-HIV prevalence settings, were the second most important types of occupation $(p<0.001)$. The detailed socio-demographic characteristics of the respondents are presented in Table 3.

\section{Characteristics of ANC/ PMTCT services visits}

Of all the study participants, 58 and $42 \%$ attended the health facilities for their first pregnancy in the urban high-HIV prevalence and rural low-HIV prevalence settings, respectively. In both settings, most of the respondents were attending their first to fourth ANC visits. A pregnant woman in an urban high-HIV prevalence setting made a relatively higher number of ANC visits than one in a rural low-HIV prevalence area $(p<0.05)$. The detailed characteristics of the respondents' use of ANC/ PMTCT services are shown in Table 4. Based on this descriptive analysis, the number of visits was considered as the dependent variable in the count regression model. 
Table 3 Socio-demographic characteristics of the respondents (pregnant women attending ANC services) across urban high-HIV prevalence and rural low-HIV prevalence settings

\begin{tabular}{|c|c|c|c|}
\hline Socio-Demographic profiles & Urban high-HIV prevalence setting $n(\%)$ & Rural low-HIV prevalence setting $n(\%)$ & $P$-value \\
\hline$\overline{\text { Age }}$ & $27.2(S D=5.00)$ & $25.91(S D=5.54)$ & 0.051 \\
\hline Educational Status & & & $0.000^{\dagger}$ \\
\hline Illiterate & $21(14.4)$ & $125(85.6)$ & \\
\hline Basic Education/ read \& write & $23(54.8)$ & $19(45.2)$ & \\
\hline Primary (grade 1-8) & $57(50.4)$ & $56(49.6)$ & \\
\hline Secondary (grade 9-10) & $43(71.7)$ & $17(28.3)$ & \\
\hline Preparatory (11-12) & $22(75.9)$ & $7(24.1)$ & \\
\hline $10+$ TVET & $11(68.8)$ & $5(31.3)$ & \\
\hline College/university - Diploma & $31(67.4)$ & $15(32.6)$ & \\
\hline College/university - Degree & $26(83.9)$ & $5(16.1)$ & \\
\hline College/university - Masters & $1(100)$ & $0(0.0)$ & \\
\hline Occupation & & & $0.000^{\dagger}$ \\
\hline Permanent paid employee & $60(71.4)$ & $24(28.6)$ & \\
\hline Wage Laborer & $7(53.8)$ & $6(46.2)$ & \\
\hline Farming/ agriculture & $6(10.2)$ & $53(89.8)$ & \\
\hline Trade/business/Merchant/self-employed & $40(64.5)$ & $22(35.5)$ & \\
\hline Housewife & $102(42.5)$ & $138(57.5)$ & \\
\hline Housemaid & $9(81.8)$ & $2(18.2)$ & \\
\hline Student & $11(73.3)$ & $4(26.7)$ & \\
\hline Marital Status & & & $0.027^{\dagger+}$ \\
\hline Single & $5(100)$ & $0(0.0)$ & \\
\hline Married & $214(47.5)$ & $237(52.5)$ & \\
\hline Divorced/Separated & $9(81.8)$ & $2(18.2)$ & \\
\hline Widowed & $2(33.3)$ & $4(66.7)$ & \\
\hline Live with partner/cohabiting & $5(45.5)$ & $6(54.5)$ & \\
\hline
\end{tabular}

${ }^{\dagger}$ Statistical significance at $P<0.001$

${ }^{++}$Statistical significance at $P<0.05$

\section{Regression analysis}

Table 5 shows the results from the Poisson regression model analysis. The model estimation applied vce (robust) to make the error estimation more robust and control for minor violations related to the underlying assumptions [30]. Household income, socio-economic HIV prevalence setting (urban high-HIV prevalence, rural low HIV-prevalence) and walking distance (minutes) had a statistically significant relationship with the number of ANC visits by a pregnant woman $(\mathrm{Y})(p<0.05)$. The Poisson regression estimates that a pregnant woman from an urban high-HIV prevalence setting would be expected to make $34 \%$ more ANC visits than her rural low-HIV prevalence counterpart. In other words, if the pregnant woman lives in a rural low-HIV prevalence setting, she would be expected to make fewer ANC visits than a woman residing in an urban high-HIV prevalence area $(p<0.05)$. Holding other variables constant, a unit increase in household income would increase the expected ANC visits by $0.004 \%$. An increase in household income was thus a statistically significant factor in relation to an increase in ANC visits $(p<0.001)$. However, if the walking distance increases by a unit (a minute) the expected number of ANC visits would decrease by 0.001 . Increased walking distance was significantly associated with a lower expected number of ANC visits $(p<0.05)$.

However, model variables, such as the age of the respondent; educational status; type of occupation; proximity to educated people; a neighborhood with better living standards/good welfare services; and transport accessibility were not found to be significantly related to a pregnant woman's expected number of visits to health facilities. The model was run to estimate the incidence rate ratio (IRR), which measures the rate at which the event (ANC visits) occurs. Table 5 illustrates the IRRs estimated across the explanatory variables.

The significant explanatory variables were household income, urban-rural HIV prevalence settings and walking 
Table 4 Characteristics of the respondents accessing ANC/ PMTCT services across the urban high-HIV prevalence and rural low-HIV prevalence settings

\begin{tabular}{llll}
\hline Key variables & Urban high-HIV prevalence settings $n(\%)$ & Rural low-HIV prevalence settings $n(\%)$ & $P$-value \\
\hline $\begin{array}{l}\text { Mean months of pregnancy } \\
\text { Is this your first pregnancy? }\end{array}$ & $7.6(\mathrm{SD}=13.72)$ & & 0.105 \\
Yes & $98(58.3)$ & $70(41.7)$ & $0.001^{\dagger}$ \\
No & $136(43.2)$ & $179(56.8)$
\end{tabular}

If $\mathrm{NO}$, indicate the total number of pregnancies you have had including this one

$\begin{array}{lll}\text { Two } & 43(45.3) & 52(54.7) \\ \text { Three } & 49(55.1) & 40(44.9) \\ \text { Four } & 18(32.1) & 38(67.9) \\ \text { Five } & 11(35.5) & 20(64.5) \\ \text { Six and more } & 15(34.1) & 29(65.9)\end{array}$

Is this your first antenatal visit (1 ANC) for this pregnancy (at any health facility visited)?

$\begin{array}{lll}\text { Yes } & 98(42.2) & 134(57.8) \\ \text { No } & 136(54.2) & 115(45.8)\end{array}$

Is this your first antenatal (1 ANC) visit at this facility for this pregnancy?

$\begin{array}{lll}\text { Yes } & 100(41.7) & 140(58.3) \\ \text { No } & 134(55.1) & 109(44.9)\end{array}$

If $\mathrm{NO}$, please tell us the total number of ANC visits you have had including this one

$\begin{array}{lll}\text { Two } & 44(48.9) & 46(51.1) \\ \text { Three } & 36(48.6) & 38(51.4) \\ \text { Four } & 21(50.0) & 21(50.0) \\ \text { Five } & 11(78.6) & 3(21.4) \\ \text { Six and more } & 22(100.0) & 0(0.0)\end{array}$

${ }^{\dagger}$ Statistical significance at $P<0.05$

Table 5 Poisson regression model result (estimate of incidence rate ratio) applying the robust error estimation

\begin{tabular}{|c|c|c|c|c|}
\hline \multicolumn{2}{|l|}{$\begin{array}{l}\text { Poisson, irr } \\
\text { Poisson regression }\end{array}$} & \multicolumn{3}{|c|}{$\begin{array}{l}\text { Number of obs }=220 \\
\text { Wald chi2 }(11)=88.54 \\
\text { Prob }>\text { chi } 2=0.00 \\
\text { Pseudo } R 2=0.07\end{array}$} \\
\hline Visits & IRR & $P>|z|$ & {$[95 \%$} & \\
\hline$\overline{\text { Age }}$ & 1.01 & 0.36 & 0.99 & 1.02 \\
\hline Education (literate compared to illiterate) & 1.01 & 0.92 & 0.80 & 1.28 \\
\hline Occupation (non-farm occupation compared to housewife) & 0.96 & 0.71 & 0.78 & 1.18 \\
\hline Occupation (farm/agriculture compared to housewife) & 0.99 & 0.89 & 0.80 & 1.22 \\
\hline Proximity to educated people (yes, no) & 0.94 & 0.57 & 0.78 & 1.15 \\
\hline Proximity to neighborhood with good welfare services (yes, no) & 1.09 & 0.40 & 0.89 & 1.34 \\
\hline Transport access (yes, no) & 1.03 & 0.77 & 0.83 & 1.29 \\
\hline Walking distance (minutes/hours) & 0.10 & 0.02 & 0.10 & 0.99 \\
\hline Income & 1.00 & 0.00 & 1.00 & 1.00 \\
\hline Urban-rural settings (urban high-HIV prevalence compared to rural low-HIV prevalence) & 1.40 & 0.00 & 1.14 & 1.73 \\
\hline Balanced decision-making (yes, no) & 0.95 & 0.60 & 0.79 & 1.14 \\
\hline Cons & 1.58 & 0.05 & 1.01 & 2.48 \\
\hline
\end{tabular}


distance, which had IRRs of 1.00004, 1.4023 and 0.9991, respectively (Table 4). Holding other factors constant, the percentage increase in the incidence rate of ANC visits was $0.004 \%$ for every unit increase in income. The incidence rate (of ANC visits) for urban high-HIV prevalence dwellers is 1.40 times that for the reference group (i.e., pregnant women in rural low-HIV prevalence settings), ceteris paribus. In addition, the percentage change in the incidence rate of ANC visits was a $1 \%$ decrease for every unit (minute) increase in walking distance.

\section{Statistical tests for the model}

The negative binomial model was analyzed to cross-validate the results in Table 5 and for the alpha dispersion test (a). The reported coefficient was similar in both the negative binomial and Poisson regression models. This highlights the appropriateness of the Poisson regression model estimation in eqs. 1.1-1.4 and further strengthens the statistical variables estimated for the dependent variable (i.e., the number of visits by a pregnant woman). The likelihood ratio test of alpha (a) (measure of dispersion) was zero, which informs the appropriateness of the Poisson model as a good-fit for the datasets. Moreover, the chi-square test (that measures two degrees of freedom for the exogenous variable) applied to occupation found that the variables were not statistically significant (Tables 6 and 7). The detailed results from the negative binomial regression are explained in (Additional file 1).

Applying the "estat gof" function (i.e. the goodness of fit tests for Pearson regression models), the model also showed the goodness-of-fit chi-square measure. Table 6 shows that the Pearson goodness-of-fit was not statistically significant; this indicates that the model did fit the datasets well. Moreover, the dispersion test alpha (a), and mean and variance were equal, which substantiates and validates the model results using the Poisson regression model.

\section{Discussion}

According to the Poisson regression model, a pregnant woman from an urban high-HIV prevalence setting would be expected to make more ANC visits (counts) than her rural low-HIV prevalence counterpart. A

Table 6 Two degrees of freedom of chi-square test for explanatory variable 'occupation' (a: negative binomial and b: Poisson model)

\begin{tabular}{|c|c|c|c|}
\hline \multicolumn{2}{|c|}{. test 1. Occupation 2. Occupation } & \multicolumn{2}{|c|}{. test 1. Occupation 2. Occupation } \\
\hline (1) & [Visits] 1. Occupation $=0$ & (1) & [Visits] 1. Occupation = 0 \\
\hline \multirow[t]{4}{*}{ (2) } & [Visits] 2. Occupation =0 & (2) & [Visits] 2. Occupation =0 \\
\hline & $\operatorname{chi} 2(2)=0.12$ & & $\operatorname{chi} 2(2)=0.14$ \\
\hline & Prob $>$ chi $2=0.9431$ & & Prob $>$ chi $2=0.9314$ \\
\hline & (a: negative binomial) & & (b: Poisson) model \\
\hline
\end{tabular}

Table 7 Statistical test (estat gof) for the Poisson model function

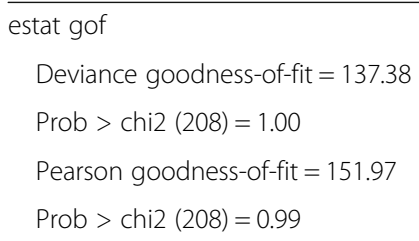

pregnant woman residing in a rural low-HIV prevalence setting would be expected to make fewer ANC visits compared to a woman residing in an urban high-HIV prevalence setting $(p<0.05)$. Other studies have also indicated the limited effectiveness of PMTCT services in rural remote areas $[9,12,13]$ and have highlighted the relevance of socio-economic (urban-rural) factors in explaining PMTCT service uptake $[9,31]$. Malaju and Alene's study in north-western Ethiopia found that PMTCT service acceptability/utilization patterns were associated with the number of ANC visits made by pregnant women residing in urban versus rural settings $[19,32]$.

Household income is also significantly associated with a higher number of ANC visits, and hence contributes to improved PMTCT service uptake. Various studies support this finding. For instance, a systematic review of 28 studies in developing countries noted that household economic factors and women's employment are critical factors in determining the use of ANC services [33]. Family income and women's employment status also play a significant role in the uptake of overall maternal and child health services [34, 35].

Other studies have reported that, from the patient perspective, economic circumstances and household income are determinants of the utilization of maternal and child health care services. Newacheck and Kim examined the effect of OOP expenses on service utilization, particularly for special health needs [36]. Out-of-pocket expenses (for service fees and transportation) incurred by a pregnant woman or her household have been found to influence service utilization among those attending ANC [37, 38]. Given the lack of social health insurance schemes in SSA, OOP spending accounts for one- to two-thirds of a patient's total health expenditure [39]. The most recent Ethiopian National Health Account reported that OOP spending accounted for $33 \%$ of total spending in the sector [40], which possibly affects the overall health sector utilization pattern. In sum, OOP expenses affect household consumption, and have been found to be a deterrent to utilization of health care, including PMTCT services [41].

The model analysis also highlights the significant relationship between walking distance to a health facility and PMTCT service utilization. PMTCT utilization studies in South Africa confirm this finding [9-11]. Skinner et al. analyzed PMTCT service utilization in the Eastern Cape town of Flagstaff [9], which is one of the poorest 
and most underdeveloped communities in South Africa. The qualitative findings from in-depth interviews and focus group discussions showed that long travelling distances and inaccessible transportation facilities were the two key barriers to utilizing PMTCT services [9]. A similar study in rural Mali that focused on the factors determining maternal health service utilization [42] also reported that service inaccessibility and transportation problems were critical barriers.

We did not find any statistically significant relationship between PMTCT service utilization and age; educational status; type of occupation; decision-making in the household; living in proximity to educated people; a neighborhood with good welfare services, and transportation accessibility. However, other studies have reported that most of these factors impact on PMTCT service uptake [34, 43]. While they used a different method employing qualitative analysis techniques, Peltzer et al. (2007) also found that transportation or geographical inaccessibility, limited family or community support, and communication facilities were critical deterrents to effective PMTCT service utilization $[10,11]$.

Although this analysis highlighted the critical factors that impact on the utilization of PMTCT services, the study has important limitations. In order to accommodate urban-rural HIV heterogeneity, the health facilities were selected purposively and this may affect the national representativeness of our findings. In addition, due to the limited availability of data, additional potential explanatory variables, namely, quality of health care, adherence and loss to follow-up, and availability of trained healthcare providers were not considered in the regression model, which probably alters the findings. We strongly recommend that both these demand and supply-side factors should be considered in future regression model analysis.

\section{Conclusion}

In contrast to most developed countries, PMTCT programs have been poorly implemented in a fragmented manner in limited-resource SSA countries. In Ethiopia in particular, antiretroviral treatment coverage for HIV-positive pregnant women and their infants was less than $50 \%$. In light of the current universal health coverage agenda, strategies to address this situation and increase the uptake of PMTCT services include women's economic empowerment, according high priority to rural low-HIV prevalence settings, and enhancing transportation accessibility. Health policy makers and program implementers need to take these three factors into account in seeking to expand PMTCT service packages for those in need, and to achieve the 90-90-90 UNAIDS target in limited resource settings. On the other hand, the real impact of these factors (urban-rural HIV prevalence, income status and waking distance) on the HIV epidemic transmission needs to be assessed in the future.

\section{Additional file}

Additional file 1: Negative binomial regression analysis results on the number of visits by the pregnant women. (DOCX $18 \mathrm{~kb}$ )

\section{Abbreviations \\ ANC: Antenatal care; EFY: Ethiopian fiscal year; EPHI: Ethiopian Public Health Institute; IRR: Incidence rate ratio; LMICs: Low- and middle-income countries; OOP: Out-of-pocket; PMTCT: Prevention of Mother-to-Child HIV Transmission; SDG: Sustainable development goals; SNNP: South Nation and nationality people; SSA: Sub-Saharan Africa; UN: United Nations; UNAIDS: Joint United Nations Program on HIV/AIDS}

\section{Acknowledgments}

We are grateful to the Federal Ministry of Health (FMOH), Ethiopian Public Health Institute (EPHI), Federal HIV/AIDS Prevention and Control Office (FHAPCO), Addis Ababa City Administration Health Bureau, Dire Dawa City Administration Health Bureau, Amhara Regional Health Bureau, Oromia Regional Health Bureau, SNNP Regional Health Bureau and Harari Regional Health Bureau for facilitating data collection, and providing administrative support for such. We are thankful to the University of KwaZulu-Natal (UKZN), Health Economics and HIV/AIDS Research Division (HEARD) for supplementary stipend support and to the Ethiopian Public Health Institute (EPHI) for its technical assistance.

We extend our gratitude to Sisay Shine for overseeing and supervising data collection and Mahre, Seble, Wozef, Seifu, Feyessa, Esubalew, Sherube, Mesgana, Yibeltal, Wuberest, Tigist and Hannan for conducting data collection in 12 health facilities. Last, but not least, we appreciate the English editing services provided by Carol Brammage.

\section{Funding}

This research was funded by an African Doctoral Dissertation Research Fellowship award offered by the African Population and Health Research Centre (APHRC) in partnership with the International Development Research Center (IDRC).

\section{Availability of data and materials}

Data from this study are available to researchers who meet the criteria for access to confidential data and are available from one of the co-

investigators, Elias Asfaw, who can be contacted at

easfaw@clintonhealthaccess.org

\section{Authors' contributions}

EA designed the study plan, prepared the data collection tools, developed the utilization analysis framework, led data collection, analyzed the data, and drafted and revised the manuscript; JM oversaw data collection, commented on the analysis plan, and reviewed and revised the manuscript; and ZTD commented on the overall analysis and the study results and revised the article. All authors read and approved the final manuscript.

\section{Ethics approval and consent to participate}

The research proposal was submitted to and approved by the University of KwaZulu-Natal's Biomedical Research Ethics Committee (BREC REF: 385/14) and the Ethiopian Public Health Institute, Scientific and Ethical Review Office (SERO REF: 6.13/80). An official letter of permission to conduct the research in the regional health bureaus and surveyed health facilities was obtained from the Federal Ministry of Health (FMOH) and Ethiopian Public Health Institute (EPHI). Informed written consent was obtained from the study participants before commencing data collection. A signatory format was used to capture every respondent's consent. Each questionnaire was coded to facilitate smooth and ethical data collection. Finally, data collection was confidential and the data was anonymously analyzed. 


\section{Consent for publication}

The study's objectives were explained to all study participants. Consent for publication was obtained from every respondent. Once the respondent agreed, data collection was conducted in a space that ensured confidentiality and privacy, and the data was anonymously analyzed.

\section{Competing interests}

The authors declare that they have no competing interests.

\section{Publisher's Note}

Springer Nature remains neutral with regard to jurisdictional claims in published maps and institutional affiliations.

\section{Author details}

${ }^{1}$ School of Accounting, Economics and Finance, Economics Department, University of KwaZulu-Natal, Durban, South Africa. ${ }^{2}$ Clinton Health Access Initiative, Health Care Financing Program, Addis Ababa, Ethiopia. ${ }^{3}$ African Population and Health Research Center, Statistics and Survey Unit, Nairobi, Kenya.

Received: 13 September 2017 Accepted: 1 November 2018

Published online: 19 November 2018

\section{References}

1. UNAIDS 2016. Feature Story: Preventing mother-to-child transmission of HIV. http://www.unaids.org/en/resources/presscentre/featurestories/2016/ october/20161024_EMotherToChildT. Accessed 13 July 2017.

2. UNAIDS. Global report: UNAIDS report on the global AIDS epidemic 2012. Joint United Nations Programme on HIV/AIDS. Geneva: United Nations Programme on HIV and AIDS; 2012.

3. UNAIDS. Global report: UNAIDS report on the global AIDS epidemic 2013. Joint United Nations Programme on HIV/AIDS. Geneva: United Nations Programme on HIV and AIDS; 2013.

4. Bauermeister JA, Tross S, Ehrhardt AA. A review of HIV/AIDS system-level interventions. AIDS Behav. 2009;13:430-48.

5. Rotheram-Borus MJ, Swendeman D, Chovnick G. The past, present, and future of HIV prevention: integrating behavioral, biomedical, and structural intervention strategies for the next generation of HIV prevention. Annu Rev Clin Psychol. 2009;5:143.

6. UNAIDS. 2014 global report on the global plan: towards the elimination of new HIV infections among children by 2015 and keeping their mothers alive. Joint United Nations Programme on HIV/AIDS. Geneva: United Nations Programme on HIV and AIDS; 2014

7. Paintsil E, Andiman WA. Update on successes and challenges regarding mother-to-child transmission of HIV. Curr Opin Pediatr. 2009;21:94.

8. Adetokunboh $\mathrm{O}$, Oluwasanu M. Eliminating mother-to-child transmission of the human immunodeficiency virus in sub-Saharan Africa: the journey so far and what remains to be done. J Infect Public Health. 2015:9(4):396-407.

9. Skinner D, Mfecane S, Gumede T, Henda N, Davids A. Barriers to accessing PMTCT services in a rural area of South Africa. Afr J AIDS Res. 2005:4:115-23.

10. Peltzer K, Skinner D, Mfecane S, Shisana O, Nqeketo A, Mosala T. Factors influencing the utilisation of prevention of mother-to-child-transmission (PMTCT) services by pregnant women in the eastern cape, South Africa: research. Health SA Gesondheid. 2005;10:26-40.

11. Peltzer K, Mosala T, Shisana O, Nqueko A, Mngqundaniso N. Barriers to prevention of HIV transmission from mother to child (PMTCT) in a resource poor setting in the eastern cape, South Africa: original research article. Afr J Reprod Health. 2007;11:57-66.

12. Peltzer K, Mosala T, Dana P, Fomundam H. Follow-up survey of women who have undergone a prevention of mother-to-child transmission program in a resource-poor setting in South Africa. J Assoc Nurses AIDS Care. 2008;19: 450-60.

13. Bajunirwe F, Muzoora M. Barriers to the implementation of programs for the prevention of mother-to-child transmission of HIV: a cross-sectional survey in rural and urban Uganda. AIDS Res Ther. 2005;2:1-7.

14. Sarker M, Sanou A, Snow R, Ganame J, Gondos A. Determinants of HIV counselling and testing participation in a prevention of mother-to-child transmission programme in rural Burkina Faso. Tropical Med Int Health. 2007;12:1475-83.
15. UN 2011. 65/277. Political Declaration on HIV and AIDS: Intensifying Our Efforts to Eliminate HIV and AIDS. United Nations General Assembly.

16. Grove J, Claeson M, Bryce J, Amouzou A, Boerma T, Waiswa P, Victora C. Maternal, newborn, and child health and the sustainable development goals_a call for sustained and improved measurement. Lancet. 2015;386: 1511-4.

17. Karamagi CA, Tumwine JK, Tylleskar T, Heggenhougen K. Antenatal HIV testing in rural eastern Uganda in 2003: incomplete rollout of the prevention of mother-to-child transmission of HIV programme? BMC Int Health Hum Rights. 2006;6:6.

18. FHAPCO. HIV/AIDS in Ethiopia an Epidemiological Synthesis. Addis Ababa: Federal HIV/AIDS Prevention and Control Office; 2013.

19. Malaju MT, Alene GD. Assessment of utilization of provider-initiated HIV testing and counseling as an intervention for prevention of mother to child transmission of HIV and associated factors among pregnant women in Gondar town, north West Ethiopia. BMC Public Health. 2012:12:1.

20. Mirkuzie AH, Hinderaker SG, Mørkve O. Promising outcomes of a national programme for the prevention of mother-to-child HIV transmission in Addis Ababa: a retrospective study. BMC Health Serv Res. 2010;10:267.

21. FMOH. Health Sector Transformation Plan (HSTP), 2015/16-2019/20. Addis Ababa: Federal Ministry of Health; 2015.

22. $\mathrm{FMOH}$. Annual performance report 2011/12. Addis Ababa: Federal Ministry of Health; 2012

23. EPHI. Report on the 2012 round antenatal case based sentinel surveillance in Ethiopia. Ethiopian Public Health Institute. Addis Ababa. In: Ethiopia; 2014

24. EHNRI 2012. HIV Related Estimates and Projections for Ethiopia. Addis Ababa: Ethiopian Health and Nutrition Research Institute, Federal Ministry of Health; 2012.

25. ECSA. Population and housing census projection. Addis Ababa: Ethiopian Central Statistical Authority; 2007

26. FMOH. Health and Health indicator report 2011/12. Addis Ababa: Federal Ministry of Health: Policy planning Directorate; 2013.

27. Naing L, Winn T, Rusli B. Practical issues in calculating the sample size for prevalence studies. Arch Orofac Sci. 2006;1:9-14.

28. Mekonnen T, Habtamu T, Tewodros G, Atkure D, Abebe B, Arega Z, Mesele M, Mengistu K, Fekadu B, Amha K. Implementation Status and Client Satisfaction of Focused Antenatal Care (FANC) in Ethiopia. Bahir dar: Ethiopian Public Health Association 26th Annual Conference; 2015.

29. Alexander N. Review: analysis of parasite and other skewed counts. Tropical Med Int Health. 2012;17:684-93.

30. Cameron AC, Trivedi PK. Microeconomics using stata. College Station: Stata press publications; 2009

31. Addai I. Determinants of use of maternal-child health services in rural Ghana. J Biosoc Sci. 2000;32:1-15.

32. Malaju MT, Alene GD. Determinant factors of pregnant mothers' knowledge on mother to child transmission of HIV and its prevention in Gondar town, north West Ethiopia. BMC Pregnancy Childbirth. 2012;12:1.

33. Simkhada B, Teijlingen ERV, Porter M, Simkhada P. Factors affecting the utilization of antenatal care in developing countries: systematic review of the literature. J Adv Nurs. 2008;61:244-60.

34. Patience Aseweh A, Gordon A-N, Sakyi K, Charles KDA, Abor J. The socioeconomic determinants of maternal health care utilization in Ghana. Int J Soc Econ. 2011;38:628-48.

35. Andersen R. A behavioral model of families' use of health services. Research Ser. 25. Chicago: Center for Health Administration Studies, University of Chicago; 1968.

36. Newacheck PW, Kim SE. A National Profile of health care utilization and expenditures for children with special health care needs. Arch Pediatr Adolesc Med. 2005;159:10-7.

37. WHO. The world health report: health systems financing, the path to universal coverage. Geneva: World Health Organization; 2010.

38. Haddad S, Fournier P. Quality, cost and utilization of health services in developing countries. A longitudinal study in Zaïre. Soc Sci Med. 1995;40: 743-53

39. WHO. World Health Organization technical meeting for the development of a framework for universal access to HIV/AIDS prevention, treatment and Care in the Health Sector. Geneva: Background paper on the concept of universal access; 2005.

40. FMOH. Ethiopia's Six National Health Accounts 2013/14. Addis Ababa: Ethiopia Federal Ministry of Health; 2017. 
41. Lagarde M, Palmer N. The impact of user fees on health service utilization in low- and middle-income countries: how strong is the evidence? World Health Organization. Bull World Health Organ. 2008;86:839-48.

42. Gage AJ. Barriers to the utilization of maternal health care in rural Mali. Soc Sci Med. 2007;65:1666-82.

43. Rai RK, Singh PK, Singh L. Utilization of maternal health care services among married adolescent women: insights from the Nigeria demographic and health survey, 2008. Womens Health Issues. 2012;22:e407-14.

Ready to submit your research? Choose BMC and benefit from:

- fast, convenient online submission

- thorough peer review by experienced researchers in your field

- rapid publication on acceptance

- support for research data, including large and complex data types

- gold Open Access which fosters wider collaboration and increased citations

- maximum visibility for your research: over $100 \mathrm{M}$ website views per year

At BMC, research is always in progress.

Learn more biomedcentral.com/submissions 